\title{
STUDIES ON THE COUMARIN ANTICOAGULANT DRUGS: THE PHARMACODYNAMICS OF WARFARIN IN MAN *
}

\author{
By ROBERT A. O'REILly, PAUL M. AGGELER, And LOIS S. LEONG
}

(From the Hematology Research Laboratory, Children's Hospital, and the Department of

Medicine, University of California School of Medicine, San Francisco, and the

Department of Medicine, Santa Clara County Hospital,

San Jose, Calif.)

(Submitted for publication March 12, 1963 ; accepted June 13, 1963)

Link (1) suggested in 1948 that the coumarin compound warfarin be used as a rodenticide. Its first human use was in a suicide attempt in 1952 (2). Although warfarin has been employed increasingly in the treatment of thromboembolic disorders (3-5), no published reports of its physiologic disposition in man have appeared, probably owing largely to the lack of a suitable method for its measurement in biologic fluids (6).

Weiner, Brodie, and Burns $(7,8)$ stated that the half-life of warfarin in man is 90 hours, but did not include the assay method, or give supporting data. In 1953, Yuyama, Goto, and Umezu (9) described a colorimetric method for the estimation of warfarin in rat plasma, but apparently this method was never applied to man. Since 1954, several investigations of warfarin in the rat have appeared, including the studies of Garner (10). Eble (11), and Lin (12). Their methods, however, were unpublished except as doctoral theses, or were not readily adaptable for studies in man.

Recently, we described a spectrophotometric method for the estimation of warfarin in biologic fluids (13), and have used this method in the present study to investigate the pharmacodynamics of warfarin in man. We determined the concentrations of warfarin in the plasma and of a warfarin metabolite in the urine of normal subjects after both oral and intravenous administration of the drug. Analysis of the data provided information on its absorption, elimination, apparent volume of distribution, and excretion. Differences in its biologic effect were evaluated by simultaneous measurements of its plasma concentration and of prothrombin complex activity.

\footnotetext{
* Work supported by U. S. Public Health Service grant $\mathrm{H}-2754$
}

\section{METHODS}

The subjects, all volunteers, were 14 normal men and women, ages 27 to 63 years, and one patient, age 72 years, with coronary artery disease who was included because he was unusually resistant to the prothrombinopenic effects of the drug.

Warfarin sodium ${ }^{1}$ was administered either orally in the form of tablets (starch base) or by iv injection. The tablets were swallowed whole in the morning by subjects in the postabsorptive state, and no food was taken for at least 2 hours thereafter. For iv administration, lyophilized warfarin sodium was reconstituted in distilled water. The total dose was injected into the antecubital vein in less than 1 minute. The dose of warfarin given by either route was based on body weight in an attempt to equalize the effect of the drug on subjects with different plasma volumes, assumed to be a function of body weight. A standard dose of $1.5 \mathrm{mg}$ per $\mathrm{kg}$ of body weight was selected so that drug levels and prothrombin complex responses would be in a clearly measurable range for several days after administration of warfarin.

Test specimens were prepared as follows. Blood obtained by clean venipuncture was mixed in glass tubes in a proportion of $9: 1$ with $3.2 \%$ sodium citrate in $0.7 \%$ saline and centrifuged at $2,000 \mathrm{rpm}$ for 20 minutes at $4^{\circ} \mathrm{C}$. The plasma was then removed and stored at $-20^{\circ} \mathrm{C}$. Twenty-four-hour urine and stool specimens were collected, and their volume and weight were recorded. Samples of each were stored at $-20^{\circ} \mathrm{C}$.

Plasma prothrombin time (prothrombin complex activity) was determined by the method of Quick (14). Thromboplastin extract was prepared from dehydrated rabbit brain 2 and stored at $-20^{\circ} \mathrm{C}$. Both control and test determinations were done on plasma stored at $-20^{\circ}$ $\mathrm{C}$ for 1 week or less and thawed just before use. Duplicate tests were done on each sample and the times averaged. The percentage of prothrombin complex activity was determined by reference to a standardization curve constructed by plotting the prothrombin time against the plasma di'ution, using $9: 10$ to $1: 10$ saline dilutions of

${ }^{1}$ Kindly supplied by Mr. Stephen Koziol, WarnerChilcott Laboratories, Morris Plains, N. J., and by Dr. Nathan Weiner, Endo Laboratories, Inc., Richmond Hill, N. Y.

2 Difco Laboratories, Detroit, Mich. 
normal plasma. Results obtained in 10 normal subjects were averaged. Uniform potency of tissue thromboplastin was insured by testing each new batch with a standard plasma specimen.

Concentrations of warfarin in plasma, urine, and aquecus suspensions of homogenized stool were measured as described previously (13). Twenty $\mathrm{ml}$ of reagent-grade ethylene dichloride ${ }^{3}$ was placed in a $60-\mathrm{ml}$ glass-stoppered bottle. Onto this organic phase were poured in a layer exactly $2 \mathrm{ml}$ of the test specimen, $1 \mathrm{ml}$ of distilled water, and $0.5 \mathrm{ml}$ of $3 \mathrm{~N} \mathrm{HCl}$. The bottle was agitated on a horizontal shaker for 2 minutes, the upper aqueous layer discarded, and all of the organic phase pipetted into a second glass-stoppered bottle. Five $\mathrm{ml}$ of $0.5 \mathrm{M}$ phosphate buffer at $\mathrm{pH} 7.25$ was poured in a layer onto the organic phase. The bottle was shaken for 5 minutes, and the upper aqueous layer discarded. Fifteen $\mathrm{ml}$ of the organic phase was placed in a third glassstoppered bottle, $4 \mathrm{ml}$ of $2.5 \mathrm{~N} \mathrm{NaOH}$ was poured in a layer over it, and the bottle was then shaken for $5 \mathrm{~min}$ utes. Enough of the upper aqueous layer was aspirated to fill a 2-ml spectrophotometer cuvette. With a Beckman model DU spectrophotometer at a slit-width setting of $0.30 \mathrm{~mm}$, the extinction was measured at $308 \mathrm{~m} \mu$, the absorption maximum, and at $360 \mathrm{~m} \mu$ for detection of interfering substances. A blank specimen and a standard containing 5 to $20 \mu \mathrm{g}$ of warfarin per $\mathrm{ml}$ were carried through each assay. The concentration of warfarin in the test specimen was derived from correlative graphs constructed from appropriate standards. With this method, the results of determinations on plasma, urine, and stool specimens stored in the frozen state for as long as several months, even when the specimens are repeatedly thawed and frozen, do not differ significantly from those on fresh specimens. The average apparent recovery of added drug was $99 \%$, with a coefficient of variation of $8 \%$ in a series of replicate analyses.

A metabolite of warfarin in urine was measured as described in a previous report (13). The urine of subjects who had taken warfarin was extracted; the ultraviolet spectrum of these extracts was of similar configuration to pure warfarin, but the peak of maximal absorption was shifted from 308 to $320 \mathrm{~m} \mu$. When these extracts were subjected to countercurrent distribution analysis, they proved to be considerably more polar than pure warfarin. Since the metabolite has not been characterized chemically, its excretion was quantitated by assuming that its ultraviolet molar extinction coefficient and that of unchanged warfarin are identical.

\section{RESULTS}

Response to a standard dose. The results of determinations on the plasma of 14 normal subjects after oral administration of a single standard dose of warfarin are listed in Tables I and II. The range and calculated mean values in the

\footnotetext{
${ }^{3}$ Fisher Scientific Corp., Boston, Mass.
}

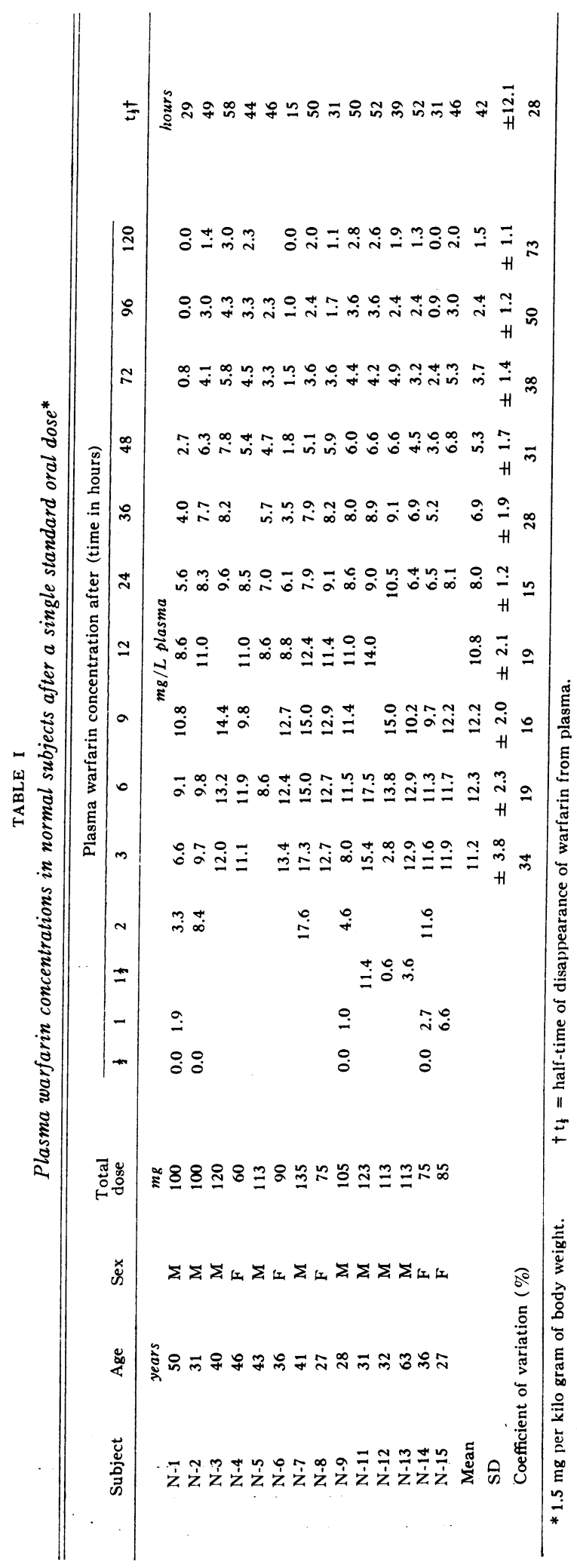


TABLE II

Prothrombin complex response in normal subjects after a single standard dose* of warfarin orally

\begin{tabular}{|c|c|c|c|c|c|c|c|c|}
\hline & \multirow[b]{2}{*}{ Subject } & \multicolumn{7}{|c|}{ Prothrombin complex activity after (time in hours) } \\
\hline & & 24 & 36 & 48 & 72 & 96 & 120 & 144 \\
\hline • & $\begin{array}{l}N-1 \\
N-2 \\
N-3 \\
N-4 \\
N-5 \\
N-6 \\
N-7 \\
N-8 \\
N-9 \\
N-11 \\
N-12 \\
N-13 \\
N-14 \\
N-15\end{array}$ & $\begin{array}{l}44 \\
46 \\
30 \\
43 \\
34 \\
36 \\
35 \\
33 \\
39 \\
37 \\
25 \\
41 \\
32 \\
43\end{array}$ & $\begin{array}{l}27 \\
22 \\
24 \\
25 \\
\\
33 \\
20 \\
22 \\
22 \\
\\
15 \\
23 \\
22\end{array}$ & $\begin{array}{l}28 \\
19 \\
13 \\
18 \\
20 \\
28 \\
12 \\
16 \\
17 \\
14 \\
11 \dagger \\
16 \\
21 \\
15\end{array}$ & $\begin{array}{c}\text { of norme } \\
31 \\
20 \\
09 \\
17 \\
16 \\
52 \\
16 \\
18 \\
17 \\
11 \\
\\
14 \\
28 \\
13\end{array}$ & $\begin{array}{l}60 \\
42 \\
09 \\
23 \\
17 \\
80 \\
23 \\
32 \\
22 \\
14\end{array}$ & $\begin{array}{l}65 \\
49 \\
11 \\
29 \\
18 \\
90 \\
36 \\
30 \\
25 \\
23 \\
\\
22 \\
46 \\
28\end{array}$ & $\begin{array}{r}71 \\
54 \\
12 \\
41 \\
25 \\
100 \\
48 \\
45 \\
33 \\
33 \\
\\
35 \\
65 \\
39\end{array}$ \\
\hline $\begin{array}{l}\text { Me } \\
\text { SD } \\
\text { Co }\end{array}$ & ent of variation $(\%)$ & $\begin{array}{l}37 \\
+\quad 6.0 \\
16\end{array}$ & $\begin{array}{r}23 \\
\pm \quad 4.5 \\
19\end{array}$ & $\begin{array}{r}18 \\
+\quad 5.3 \\
29\end{array}$ & $\begin{aligned} & 20 \\
\pm & 11.5 \\
& 57\end{aligned}$ & $\begin{aligned} & 32 \\
+ & 20.7 \\
& 64\end{aligned}$ & $\begin{array}{l}36 \\
+19.9 \\
55\end{array}$ & $\begin{aligned} & 46 \\
&+ 21.6 \\
& 47\end{aligned}$ \\
\hline
\end{tabular}

* $1.5 \mathrm{mg}$ per kilogram of body weight.

$\dagger$ Subject took $10 \mathrm{mg}$ of vitamin $K_{1}$ orally at this time.

group are shown in Figure 1. As Table I shows, the absorption phase was characterized by a rapid rise in plasma drug concentration, which reached maximal values of 8.6 to $17.6 \mathrm{mg}$ per L in 2 to 12 hours. Thereafter, during the phase of elimination, the concentrations declined exponentially, reaching values of 0 to $3 \mathrm{mg}$ per L by 120 hours. The mean, standard deviation, and coefficient of variation $(\mathrm{CV})$ were calculated for each period, beginning at 3 hours. At 3 hours, the plasma concentrations showed considerable variation $(\mathrm{CV}=$ $34 \%$ ), apparently due to differing rates of gastrointestinal absorption. From 6 to 24 hours, drug absorption was completed and the elimination phase began; variation was least during this time $(\mathrm{CV}=15$ to $19 \%)$. After 24 hours, the plasma concentrations again showed increasing variation ( $\mathrm{CV}=73 \%$ at 120 hours), reflecting differing rates of elimination of warfarin.

Prothrombin complex activity (Table II) was significantly reduced in all subjects within 24 hours; maximal reductions were reached between 36 and 72 hours. There was little variation between subjects during the first 24 hours, followed by increasing variation throughout the remainder of the period of observation, as the large coeffcients of variation after 48 hours indicate.

The biologic half-time of disappearance $\left(t_{t}\right)$ of warfarin in each subject was determined from the final exponential component of the disappearance curve. As shown in Table I and Figure 1, the $t_{\frac{1}{2}}$ of warfarin in the group ranged from 15 to 58 hours, with a mean of 42 hours. The subject with the slowest clearance of warfarin from the plasma $\left(\mathrm{N}-3, \mathrm{t}_{\frac{1}{2}}=58\right.$ hours $)$ had the greatest prothrombin time response, whereas the subject with

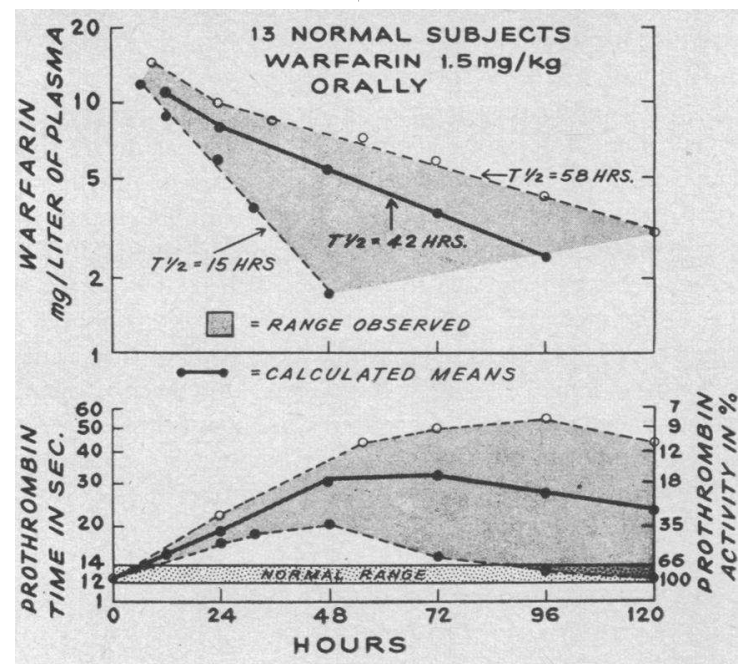

Fig. 1. Range and MEan OF WARfarin CONCENTRaTION IN PLASMA AND OF PROTHROMBIN TIME AFTER A SINGLE ORAL DOSE OF WARFARIN (1.5 MG PER KG BODY் WEIGHT) IN 13 NORMAL SUBJECTS. Data on Sulject N-12 were omitted because ingestion of vitamin $\mathrm{K}$ altered the prothrombin response. 
TABLE III

Plasma warfarin concentration in normal subject (N-1) after various doses of drug orally

\begin{tabular}{|c|c|c|c|c|c|c|c|c|c|c|}
\hline \multirow{2}{*}{$\begin{array}{l}\text { Total } \\
\text { dose }\end{array}$} & \multirow[b]{2}{*}{ Dose } & \multicolumn{9}{|c|}{ Plasma warfarin concentration after (time in hours) } \\
\hline & & $\frac{1}{2}$ & 1 & 2 & 3 & 4 & 6 & 8 & 9 & 12 \\
\hline$m g$ & $\begin{array}{c}m g / k g \\
b o d y ~ w t\end{array}$ & \multicolumn{9}{|c|}{$m g / L$ plasma } \\
\hline $\begin{array}{r}50 \\
100 \\
200\end{array}$ & $\begin{array}{l}0.75 \\
1.50 \\
3.00\end{array}$ & $\begin{array}{l}0.0 \\
0.0 \\
0.0\end{array}$ & $\begin{array}{l}0.6 \\
1.9 \\
2.1\end{array}$ & $\begin{array}{r}1.3 \\
3.3 \\
14.0\end{array}$ & $\begin{array}{r}2.0 \\
9.0 \\
19.2\end{array}$ & $\begin{array}{r}3.3 \\
9.4 \\
22.9\end{array}$ & $\begin{array}{r}5.4 \\
9.5 \\
24.7\end{array}$ & 25.1 & $\begin{array}{r}5.9 \\
10.4 \\
24.0\end{array}$ & $\begin{array}{r}4.2 \\
8.4 \\
18.1\end{array}$ \\
\hline
\end{tabular}

the most rapid clearance $\left(\mathrm{N}-6, \mathrm{t}_{1}=15\right.$ hours $)$ had the least. The mean prothrombin time responses at 48 and 72 hours were nearly equal; in the most responsive subject the prothrombin time was longer at 72 than at 48 hours, whereas in the least responsive subject the converse was true.

The relationship between the pharmacologic behavior of warfarin as represented by its plasma concentration and $t_{t}$ and the biologic response as represented by the prothrombin complex activity is illustrated graphically in Figure 2. A high degree of correlation was found (at 48 hours, $r=-$ $0.86, \mathrm{p}<0.001)$. A similarly significant correlation was found between the $t_{1}$ and maximal prothrombinopenic response $(r=-0.93, p<0.001)$.
Absorption. The duration of gastrointestinal absorption, as determined by the time of onset of the final exponential component of the disappearance curve (15), was 6 to 24 hours after administration of a single standard dose of warfarin (Figure 1). To determine the time of absorption more exactly, experiments with more frequent sampling were carried out in three normal subjects $(\mathrm{N}-1$, $\mathrm{N}-9$, and $\mathrm{N}-14$ ). The concentration of warfarin in the plasma of these subjects rose to maximal levels in 2 to 9 hours (Table I).

Similar studies were carried out on one subject $(\mathrm{N}-1)$ after oral administration of 50,100 , and $200 \mathrm{mg}$ of warfarin. The plasma concentrations of warfarin in this subject are shown in

TABLE IV

The volume of distribution and plasma elimination of warfarin after single iv doses of drug in 6 normal subjects and 1 patient*

\begin{tabular}{|c|c|c|c|c|c|c|c|c|c|}
\hline Subject & $\begin{array}{c}\text { Body } \\
\text { wt }\end{array}$ & $\begin{array}{l}\text { Total } \\
\text { dose }\end{array}$ & Dose & $C_{p^{0}}$ & $V_{d}$ & $\mathrm{~V}_{\mathrm{d}}$ & $\frac{V_{d}}{P V}$ & $t_{\frac{1}{2}}$ & $\mathbf{K}$ \\
\hline & $k g$ & $m \boldsymbol{g}$ & $\begin{array}{c}m g / k g \\
b o d y ~ w t\end{array}$ & $\underset{\text { plasma }}{m g / L}$ & $L$ & $\begin{array}{c}\% \underset{w t}{\text { body }} \\
\text { w }\end{array}$ & & hours & hour -1 \\
\hline \multirow[t]{3}{*}{$\begin{array}{l}\text { N-2 } \\
N-2 \\
N-3 \\
N-2 \\
N-4 \\
N-6 \\
N-1 \\
N-1 \\
N-2 \\
N-1 \\
N-1 \\
N-13\end{array}$} & $\begin{array}{l}68 \\
68 \\
80 \\
68 \\
40 \\
59 \\
65 \\
65 \\
68 \\
65 \\
65 \\
75\end{array}$ & $\begin{array}{r}50 \\
50 \\
100 \\
100 \\
60 \\
89 \\
100 \\
100 \\
200 \\
200 \\
200 \\
600\end{array}$ & $\begin{array}{l}0.75 \\
0.75 \\
1.25 \\
1.25 \\
1.50 \\
1.50 \\
1.50 \\
1.50 \\
3.00 \\
3.00 \\
3.00 \\
8.00\end{array}$ & $\begin{array}{r}5.8 \\
5.6 \\
12.9 \\
13.0 \\
12.8 \\
10.3 \\
10.8 \\
13.0 \\
26.0 \\
20.8 \\
22.0 \\
50.1\end{array}$ & $\begin{array}{r}8.6 \\
8.9 \\
7.8 \\
7.7 \\
4.7 \\
8.7 \\
9.3 \\
7.7 \\
7.7 \\
9.6 \\
9.1 \\
11.9\end{array}$ & $\begin{array}{r}12.6 \\
13.1 \\
9.8 \\
11.3 \\
11.7 \\
14.8 \\
14.2 \\
11.8 \\
11.3 \\
14.8 \\
14.0 \\
15.8\end{array}$ & $\begin{array}{l}2.5 \\
2.6 \\
2.0 \\
2.3 \\
2.4 \\
3.0 \\
2.8 \\
2.4 \\
2.3 \\
3.0 \\
2.8 \\
3.2\end{array}$ & $\begin{array}{l}40 \\
40 \\
47 \\
38 \\
55 \\
21 \\
17 \\
23 \\
48 \\
28 \\
24 \\
44\end{array}$ & $\begin{array}{l}0.017 \\
0.017 \\
0.015 \\
0.018 \\
0.013 \\
0.033 \\
0.014 \\
0.030 \\
0.014 \\
0.025 \\
0.029 \\
0.016\end{array}$ \\
\hline & & & & Mean & & 12.8 & 2.6 & 36 & 0.020 \\
\hline & & & & $\mathrm{SD}$ & & \pm 2.2 & & & \\
\hline$P-3$ & 55 & $\begin{array}{r}82 \frac{1}{2} \\
330^{2} \\
1,010\end{array}$ & $\begin{array}{r}1.50 \\
6.00 \\
18.38\end{array}$ & $\begin{array}{l}10.5 \\
41.1 \\
128\end{array}$ & $\begin{array}{l}7.9 \\
8.0 \\
7.9\end{array}$ & $\begin{array}{l}14.0 \\
14.0 \\
14.0\end{array}$ & $\begin{array}{l}2.8 \\
2.8 \\
2.8\end{array}$ & $\begin{array}{l}57 \\
51 \\
51\end{array}$ & $\begin{array}{l}0.012 \\
0.014 \\
0.014\end{array}$ \\
\hline
\end{tabular}

${ }^{*} \mathrm{C}_{\mathrm{p}}{ }^{0}=$ concentration at zero time $; \mathrm{V}_{\mathrm{d}}=$ volume of distribution of warfarin; $\mathrm{V}_{\mathrm{d}} / \mathrm{PV}=$ ratio of $\mathrm{V}_{\mathrm{d}}$, expressed as percentage of body weight, to plasma volume, assuming the latter to be $5 \%$ of body weight; $t_{\frac{1}{2}}=$ half-time of disappeara nce of warfarin; and $\mathrm{K}=$ first-order rate constant. 
Table III; the concentration rose slowly to a maximum after $50 \mathrm{mg}$ of warfarin, rose abruptly and rapidly after $200 \mathrm{mg}$, and was intermediate after $100 \mathrm{mg}$.

The extent of gastrointestinal absorption was evaluated by determination of the warfarin content in the stool after both oral and iv administration of the drug. Warfarin was not detectable in the stool during any experiment, even after oral administration of $6 \mathrm{mg}$ per $\mathrm{kg}$ of body weight (400 mg).

Plasma elimination and volume of distribution. The disappearance of warfarin from the plasma was studied by iv administration of the drug. During the first few hours, plasma levels declined steeply, then more slowly, eventually following an exponential course for the remainder of the experiment. In all experiments in which a sufficient number of observations were made, the data could be fitted to a triple exponential decay pattern. In most experiments, the number of early observations was insufficient to allow for separation of the first and second components, so that only the third component has been analyzed ( $\mathrm{Ta}$ -

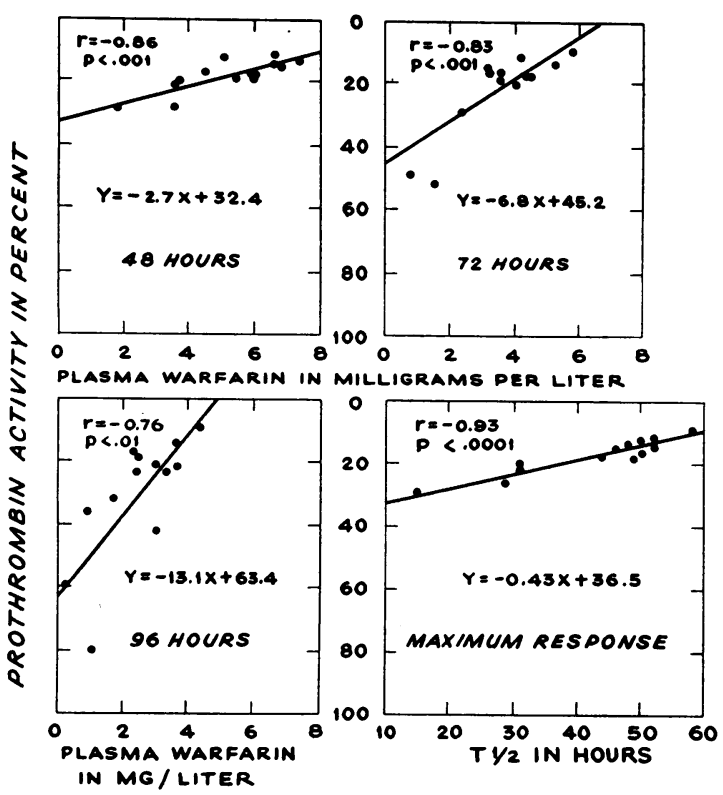

Fig. 2. RELATIONShip OF PROThROMbIN COMPLEX ACTIVITY AT 48, 72, AND 96 HOURS TO PLASMA WARFARIN CONCENTRATION, AND THE RELATIONSHIP OF MAXIMAL PROTHROMBIN COMPLEX RESPONSE TO THE HALF-TIME OF DISAPPEARANCE OF WARFARIN AFTER A SINGLE ORAL DOSE (1.5 MG PER KG BODY WEIGHT) IN 13 NORMAL SUBJECTS.
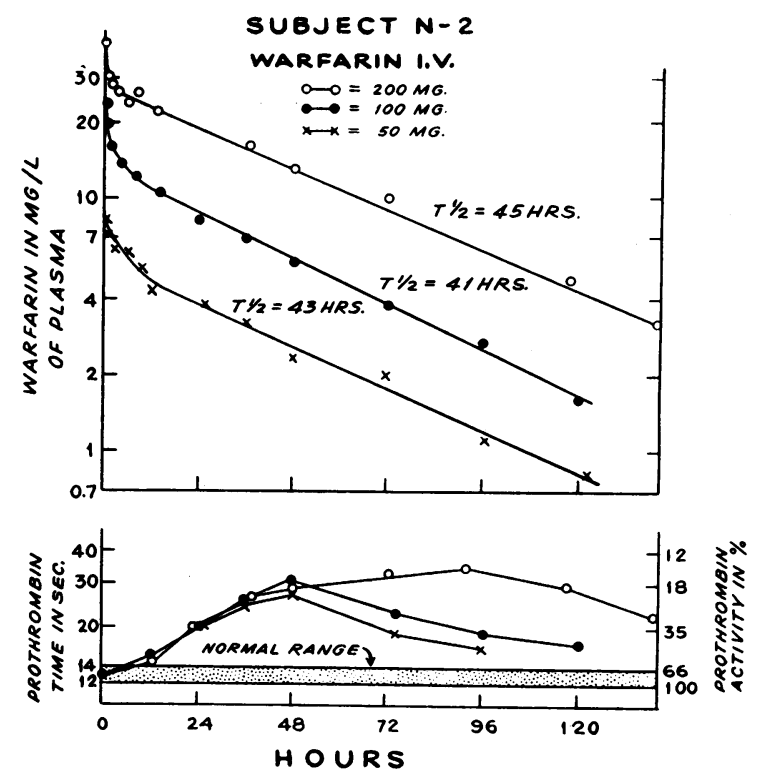

Fig. 3. Plasma concentration of warfarin and PROTHROMBIN RESPONSE AFTER SINGLE IV DOSES OF 0.75 , 1.5, AND 3.0 MG PER KG BODY WEIGHT (50, 100, AND 200 MG) IN A NORMAL SUBJECT (N-2).

ble IV). Twelve experiments were performed on 6 normal subjects, and 3 experiments on the drugresistant patient, $\mathrm{P}-3$. In the normal subjects, the total dose varied from 0.75 to $8.00 \mathrm{mg}$ per $\mathrm{kg}$ body weight. The $t_{1}$ ranged from 17 to 55 hours, with a mean of 37 hours. The corresponding mean value for the first-order rate constant, $\mathrm{K}$, was 0.019 hour $^{-1}$, indicating an instantaneous plasma elimination rate due to this component of $1.9 \%$ per hour.

Subject N-2 received single iv doses of 50,100 , and $200 \mathrm{mg}$ of warfarin during separate experiments. The data are shown in Figure 3. Close agreement was found in the $t_{1}$ at the three dose levels ( 41 to 45 hours). Subject $\mathrm{N}-1$ received single doses of $50,150,400$, and $800 \mathrm{mg}$ of warfarin orally. The $t_{1}$ was virtually identical in all four experiments ( 24 to 30 hours). Even when the very resistant subject (P-3) was given 1,010 $m$ of warfarin in a single iv dose, the $t_{1}$ was identical with that found when he was given smaller doses.

To determine if warfarin entered the red blood cells, $\mathrm{C}^{14}$-labeled warfarin ${ }^{4}$ was added to citrated

${ }^{4}$ Provided by Prof. K. P. Link of the University of Wisconsin School of Agriculture and by Dr. C. Schroeder of the Wisconsin Alumni Research Foundation. 
THE PHARMACODYNAMICS OF WARFARIN IN MAN

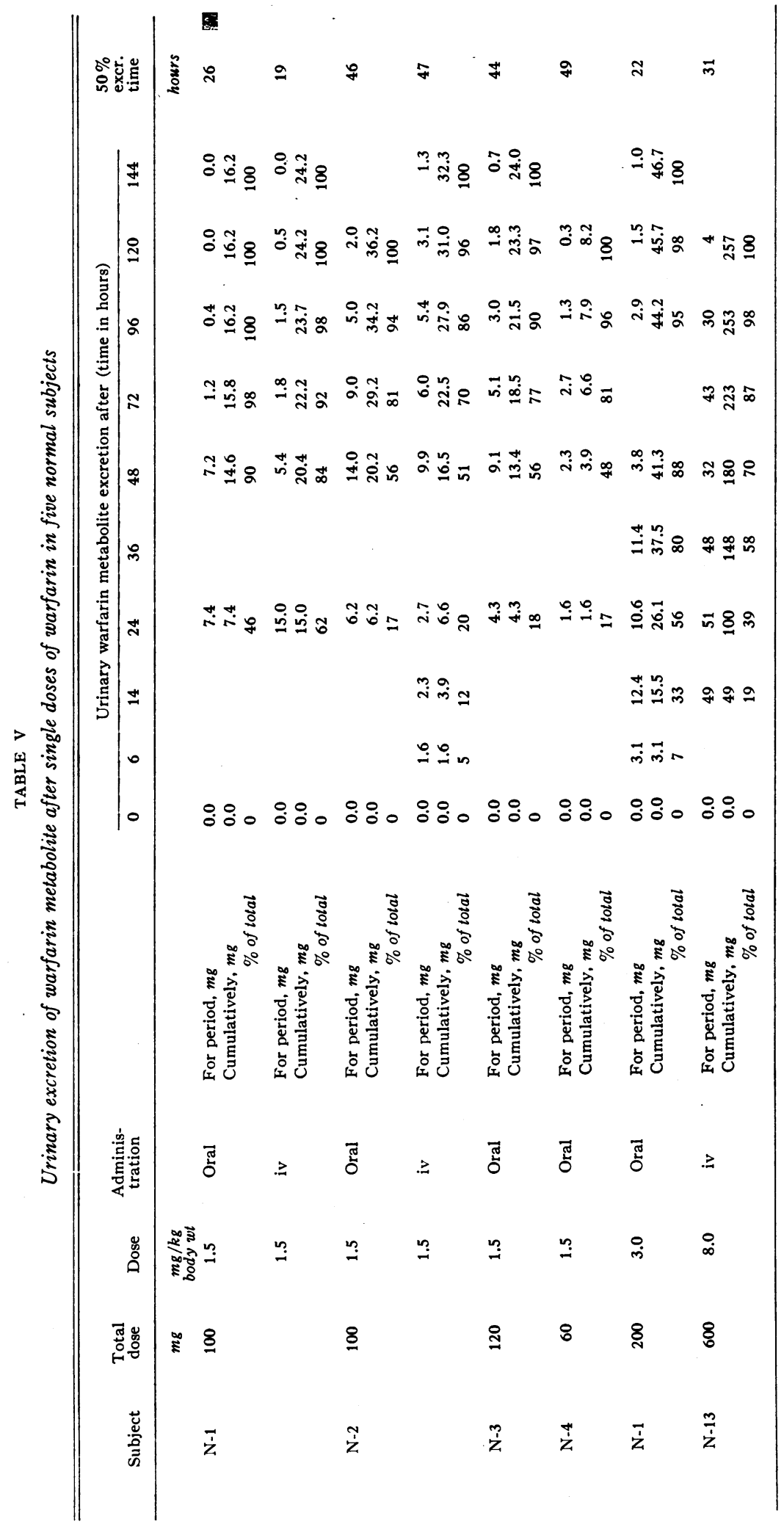


blood and incubated at $37^{\circ} \mathrm{C}$ for 2 hours. One part of the sample was hemolyzed by repeated freezing and thawing, the rest was centrifuged, and the red blood cells were separated from the plasma and washed 5 times. These three fractions were dried on planchets and counted in a $\mathrm{C}^{14}$ internal-flow gas chamber. Less than $1 \%$ of the radioactivity was found in the red-cell fraction and over $99 \%$ in the plasma. ${ }^{5}$

In these experiments, the final exponential component of the disappearance curve of intravenously administered warfarin was extrapolated back to zero time $\left(\mathrm{C}_{\mathrm{p}}{ }^{\circ}\right)$. Since warfarin appeared not to enter the red blood cells, the dose divided by the $\mathrm{C}_{\mathrm{p}}{ }^{\circ}$ gave the apparent volume of distribution $\left(V_{d}\right)$. As shown in Table IV, $V_{d}$, expressed as percentage of body weight, ranged from 9.8 to 15.8 , with a mean of $12.8 \pm 2.2$ SD. No correlation was found between the size of the dose (in milligrams per kilogram body weight) and $V_{d}$. With plasma volume assumed to be $5 \%$ of body weight, the warfarin space was $2.6 \pm 0.3$ times the plasma volume.

Excretion. In eight experiments, five normal subjects were given single oral or iv doses of 1.5 to $8.0 \mathrm{mg}$ of warfarin per $\mathrm{kg}$ body weight (60 to $600 \mathrm{mg}$ ). All stool and urine was collected for several days. No unchanged warfarin could be demonstrated in the stool at any time. We previously reported preliminary studies indicating that warfarin was present in the urine (16), but further investigation proved this to be almost entirely a metabolite of the drug (13). As shown in Table V, much larger quantities of metabolite were excreted for the two larger doses at all periods. By 96 hours, 86 to $100 \%$ of the metabolite was excreted by all subjects. Two of the subjects $(\mathrm{N}-1$ and $\mathrm{N}-2)$ received the same dose (100 $\mathrm{mg}$ ) orally and intravenously. Little difference was observed in the cumulative excretion pattern. The time required for excretion of $50 \%$ of the metabolite ranged from 19 to 49 hours.

Effect of vitamin $K$ on warfarin metabolism. In three experiments, two subjects received 5 to 10 $\mathrm{mg}$ of vitamin $\mathrm{K}_{1}$ orally 3 times daily for 3 days. On day $4,1.5 \mathrm{mg}$ of warfarin per $\mathrm{kg}$ body weight and $25 \mathrm{mg}$ of vitamin $\mathrm{K}_{1}$ were given simultaneously by mouth. The plasma warfarin concentra-

${ }^{5} \mathrm{We}$ are grateful to Dr. Evelyn Siris for making these determinations.
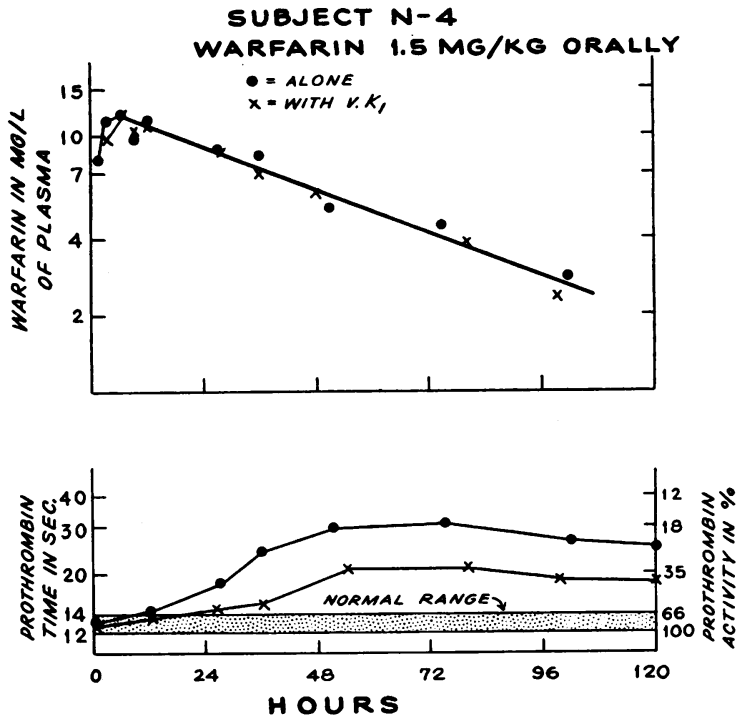

Fig. 4. EfFect of vitamin $K_{1}$ on plasma concenTRATIONS OF WARFARIN AND PROTHROMBIN RESPONSES AFTER SINGLE ORAL DOSES OF 1.5 MG PER KG BODY WEIGHT IN A NORMAL SUBJECT $(\mathrm{N}-4)$. Vitamin $\mathrm{K}_{1}$ was adm:nistered orally, $5 \mathrm{mg}$ three times daily for 4 days, and then $25 \mathrm{mg}$ simultaneously with warfarin.

tions and prothrombin complex response were determined and compared with those obtained in the same subjects after administration of warfarin alone. The results of one of these experiments are given in Figure 4. The lower graph shows the significant antidotal action of the vitamin on the prothrombin complex activity. Administration of vitamin $\mathrm{K}$ did not significantly alter the rate of absorption, the time and magnitude of the maximal concentration in plasma, or the rate of elimination of warfarin. Another normal subject $(\mathrm{N}-12)$, who received the standard dose of warfarin, took $10 \mathrm{mg}$ of vitamin $\mathrm{K}_{1}$ orally 48 hours later. Whereas prothrombin complex activity returned to the normal range within 24 hours, the rate of disappearance of warfarin from the plasma was not altered by ingestion of vitamin $\mathrm{K}$.

Prothrombin complex response. The prothrombinopenic response to warfarin was studied over a wide range of single doses in four subjects. Beyond certain critical levels, increasing the dose of warfarin did not hasten the rate of prothrombinopenic response. As shown in Figure 3, the maximal rate of prothrombin time prolongation was achieved with a dose of $50 \mathrm{mg}$ in subject $\mathrm{N}-2$. 
Increasing the dose to $200 \mathrm{mg}$ did not hasten the rate of response. There appeared to be a direct linear relationship at lower doses between the logarithm of the dose and the maximal depression of prothrombin complex activity. With higher doses, the major effect was not on the degree of maximal response but on its duration.

\section{DISCUSSION}

The marked variation in the prothrombin time response of normal subjects to similar doses of warfarin appeared to be conditioned mainly by differences in the rate of elimination of warfarin from the plasma. Since practically no unchanged warfarin was excreted in the urine and none in the stool (13), its elimination from the plasma must occur almost exclusively by chemical transformation (17). The speed of its elimination is a function of the rate of this process. The rate of elimination of warfarin from the plasma, unlike that of Dicumarol (bis-hydroxycoumarin) (18), is independent of the size of the dose or the route of administration. High degrees of correlation were found between rates of elimination and maximal prothrombinopenic responses and between plasma warfarin levels and prothrombin complex values after administration of a single large dose of warfarin. This should not be construed as a direct, cause-and-effect relationship. The prothrombin complex activity at 48 hours is not the direct result of the amount of warfarin in the plasma at that time. Rather, both values reflect events that occurred during the preceding 48 hours. Previous investigations have suggested that the prothrombinopenic response of a particular drug is related to the duration of maintenance of its plasma concentration $(7,8)$. Significant correlations between plasma warfarin concentrations and prothrombin complex values, however, could not be demonstrated. Prolonged and incomplete absorption of warfarin, often continuing for 3 to 4 days (19), made such correlations with Dicumarol impractical. With ethyl bis-coumacetate (Tromexan), in contrast, the elimination rate was so fast ( $t_{1}$, approximately 3 hours) that the major prothrombinopenic effect was not exerted until after the drug was no longer detectable in the plasma (20). We found warfarin to be ideally suited for showing these correlations because its absorption phase was complete and of short duration, and its elimination phase relatively slow.

The volume of distribution of warfarin (approximately $13 \%$ of body weight) was lower than that of most acidic drugs (25 to $30 \%$ ) (17) and was identical with that found for pure albumin (21). We previously showed that $97 \%$ of warfarin in plasma is bound to protein (16). Recent in vitro studies in our laboratory with $\mathrm{C}^{14}$ labeled warfarin indicate that it is bound by the albumin fraction in native plasma (22). These data suggest that the small size of the warfarin space is a result of its high degree of albumin binding.

The volume of distribution of warfarin, as is true of practically all drugs, was independent of the amount of drug injected. In contrast, increasing doses of Dicumarol result in smaller apparent volumes of distribution (23). The better aqueous solubility of warfarin at body $\mathrm{pH}$ (24) may result in quicker equilibration, and hence, in a $V_{d}$ that is independent of dose.

Oral administration of vitamin $\mathrm{K}_{1}$ (phytonadione) exerted an antidotal effect on the prothrombin complex response, but did not alter the gastrointestinal absorption of warfarin or its elimination from the plasma. These results confirm the findings of Eble (11) in the rat. Weiner and associates (7) stated that the simultaneous administration of vitamin $\mathrm{K}$ and Dicumarol did not alter the plasma levels of the anticoagulant in man. These reports suggest that the antidotal action of vitamin $\mathrm{K}$ on the prothrombinopenic effect of the coumarin anticoagulant drugs is not mediated through an alteration in the pharmacodynamics of the anticoagulant. The antidotal effect of vitamin $\mathrm{K}$ in animals given Dicumarol was attributed by Lee, Trevoy, Spinks, and Jaques (25) to direct displacement of the drug from the liver. These results could not be confirmed, however, by Green, Sondergaard, and Dam (26). Our results are more consistent with those of the latter group; we found no alteration in the plasma elimination curve of warfarin after administration of vitamin $\mathrm{K}_{1}$, so warfarin was not displaced from the plasma or from the liver into the plasma. In terms of competitive inhibition of vitamin $\mathrm{K}_{1}$ and warfarin in a reversible reaction, it is not necessary to postulate absolute displacement of warfarin from the liver. The facilitation or inhibition of this reac- 
tion could depend on the relative proportion of the vitamin and its structural analog, the coumarin, in the liver (27).

\section{SUM MARY}

1. The metabolism of warfarin in man was studied with a spectrophotometric method recently developed in our laboratory for the estimation of unchanged warfarin in biologic fluids. Simultaneous measurements of warfarin levels and of prothrombin complex responses were made in a variety of circumstances.

2. A standard dose of warfarin $(1.5 \mathrm{mg}$ per $\mathrm{kg}$ of body weight) was administered orally to 14 normal subjects. Maximal concentrations in plasma occurred in 2 to 12 hours. Thereafter, during the phase of elimination, the half-time of warfarin's disappearance from the plasma varied from 15 to 58 hours, with a mean of 42 hours. Maximal depression of prothrombin complex activity was achieved between 36 and 72 hours. The normal subjects with the least prothrombinopenic response to warfarin had the most rapid elimination rates, and the most responsive subjects had the slowest. In normal subjects, high degrees of correlation were found between the plasma concentrations of warfarin at 48,72 , and 96 hours and the halftime of its disappearance, and also between the plasma concentrations and the degree of prothrombin complex depression.

3 . The absorption of warfarin from the gastrointestinal tract appeared to be complete, since no warfarin was found in the stool even after massive oral doses. Furthermore, warfarin levels in plasma and prothrombin complex responses were virtually identical with oral and intravenous administration.

4. The apparent volume of distribution $\left(V_{d}\right)$, expressed as a percentage of body weight, ranged from 9.8 to 15.8 , with a mean of 12.8 . No correlation was found between the size of the dose of warfarin and $V_{d}$. The warfarin space was the same size as the albumin space (2.6 times the plasma volume).

5. Virtually no unchanged warfarin, but significant quantities of a metabolite, were found in the urine.

6. Oral administration of vitamin $\mathrm{K}_{1}$ did not influence the rates of absorption or chemical transformation of warfarin.

\section{REFERENCES}

1. Link, K. P. The discovery of Dicumarol and its sequels. Circulation 1959, 19, 97.

2. Holmes, R. W., and J. Love. Suicide attempt with warfarin, a bis-hydroxycoumarin-like rodenticide. J. Amer. med. Ass. 1952, 148, 935.

3. Shapiro, S. Warfarin sodium derivative: (Coumadin ${ }^{\circledR}$ sodium) : an intravenous hypoprothrombinemia-inducing agent. Angiology 1953, 4, 380.

4. Pollock, B. E. Clinical experience with warfarin (Coumadin) sodium, a new anticoagulant. J. Amer. med. Ass. 1955, 159, 1094.

5. Toohey, M. Clinical experience with warfarin sodium. Brit. med. J. 1958, 2, 892.

6. Wanntorp, H. Studies on chemical determination of warfarin and coumachlor and their toxicity for dog and swine. Acta pharmacol. (Kbh.) 1960, 16, suppl. 2, 1-123.

7. Weiner, M., B. B. Brodie, and J. J. Burns. A comparative study of hypoprothrombinemic agents: the physiologic disposition and chemical pharmacology of coumarin and indanedione compounds in Thrombosis and Embolism, Proc. 1st int. Conf., T. Koller and W. R. Merz, Eds. Basel, Schwabe, 1955 , p. 181.

8. Weiner, M. Pharmacologic considerations of antithrombotic therapy. Advanc. Pharmacol. 1962, 1, 277.

9. Yuyama, A., J. Goto, and M. Umezu. Biochemical studies on warfarin. I. A colorimetric method for the determination of warfarin in plasma. Igaku to Seibutsugaku 1953, 29, 147.

10. Garner, R. J. A spectroscopic study of the fate of warfarin and coumachlor in the rat. Nord. Vet.Med. 1957, 9, 464.

11. Eble, J. N. Studies on warfarin and warfarin sodium. Ph.D. thesis, University of Wisconsin, 1954.

12. Lin, T.-H. Studies on warfarin. Ph.D. thesis, University of Wisconsin, 1955.

13. O'Reilly, R. A., P. M. Aggeler, M. S. Hoag, and L. Leong. Studies on the coumarin anticoagulant drugs: the assay of warfarin and its biologic application. Thrombos. Diathes. haemorrh. (Stuttg.) 1962, 8, 82.

14. Quick, A. J. Hemorrhagic Diseases. Philadelphia, Lea \& Febiger, 1957, p. 379.

15. Swintosky, J. V. Illustrations and pharmaceutical interpretations of first-order drug elimination rate from the bloodstream. J. Amer. pharm. Ass., sci. Ed. 1956, 45, 395.

16. O'Reilly, R. A., P. M. Aggeler, M. S. Hoag, and L. Leong. The assay of warfarin and its biologic application (abstract). Blood 1961, 18, 787.

17. Nelson, E. Kinetics of drug absorption, distribution, metabolism and excretion. J. pharm. Sci. 1961, 50, 181.

18. Weiner, M., S. Shapiro, J. Axelrod, J. R. Cooper, and B. B. Brodie. The physiological disposition of 
Dicumarol in man. J. pharmacol. exp. Ther. 1950, 99, 409.

19. O'Reilly, R. A., P. M. Aggeler, M. S. Hoag, and L. S. Leong. Studies on warfarin and Dicumarol (abstract). Clin. Res. 1962, 10, 108.

20. Pulver, R., and K. N. v. Kaulla. Ueber Resorption und biologische Inaktivierung des neuen Antithromboticums Tromexan. Schweiz. med. Wschr. 1948, 78, 956.

21. Berson, S. A., R. S. Yalow, S. S. Schreiber, and J. Post. Tracer experiments with $I^{131}$-labeled human serum albumin: distribution and degradation studies. J. clin. Invest. 1953, 32, 746.

22. O'Reilly, R. A. Unpublished observations.
23. O'Reilly, R. A., P. M. Aggeler, and L. S. Leong. The distribution and elimination of warfarin and Dicumarol (abstract). Clin. Res. 1963, 11, 93.

24. Snyder, J. A. Studies on warfarin, Dicumarol and Cyclocumarol. Ph.D. thesis, University of Wisconsin, 1953.

25. Lee, C. C., L. W. Trevoy, J. W. T. Spinks, and L. B. Jaques. Dicumarol labelled with $\mathrm{C}^{14}$. Proc. Soc. exp. Biol. (N. Y.) 1950, 74, 151.

26. Green, J. P., E. Sondergaard, and H. Dam. Studies on distribution of dicumarol. Proc. Soc. exp. Biol. (N. Y.) 1956, 92, 449.

27. Woolley, D. W. Recent advances in the study of biological competition between structurally related compounds. Physiol. Rev. 1947, 27, 308. 